\title{
El simbolismo animal en la cultura medieval
}

\author{
M. ${ }^{\text {a Dolores-Carmen Morales MuÑIz }}$ \\ UNED
}

A Pachi, ictióloga.

\section{CUESTIONES DE PRINCIPIO}

Abordar un tema tan amplio y complejo como el de la simbología animal en los siglos medievales en un espacio tan corto, me obliga a seleccionar los puntos prioritarios a tratar. En primer lugar adelanto que el trabajo aquí presentado es parte de una línea de investigación más amplia sobre culturas zoológicas en la España medieval, entendiendo comparativamente a la cristiana, a la musulmana y a la judía. Como se sabe, la zoohistoria y sus implicaciones en la vida del hombre -sobre todo esto último- es una especialidad cada vez más cultivada dentro de la investigación reciente, también para la Edad Media. La simbología, dentro de aquelia especialidad, resulta uno de los aspectos más sugerentes, y en estas líneas queremos plantear los puntos más relevantes de esta contribución.

La cultura medieval, o el mundo medieval, tiene una vertiente eminentemente simbólica, a decir de muchos autores, como en casi ninguna otra época de la historia. El lenguaje simbólico abarca todos y cada uno de los aspectos de la vida del hombre desde la etimología hasta la liturgia. Le Goff afirma que ese pensamiento simbólico no era más que la forma elaborada del pensamiento mágico del que estaba imbuida la mentalidad común. Así, los símbolos harían referencia a una realidad superior, escondida y sagrada con la que había que contactar '. Dominando el lenguaje simbólico, se rendía pleitesía a un ser superior, en este caso, a

1 Jacques Le Goff La civilisation de l'Occident Médiéval pp. 371 y ss. Paris, 1984. 
Dios. El código para enlazar con Él, la forma de ser reconocidos por Él, era dominar ios signos. Además el cristianismo hace que el fenómeno simbólico, con toda la indefinición que tiene este concepto, pueda llegar a gozar de unos criterios claros, y por lo tanto, homogéneos y universales, dado que la fe cristiana es indisociable de la cultura y la vida medieval. Hay que adelantar aqui que este trabajo se centrará, por razones varias, en la cultura occidental de forma global, presentando las posibles ampliaciones a través de hipótesis que pueden dar lugar a otros trabajos ${ }^{2}$.

Habría que empezar, pues, con una generalidad que luego convendría matizar: el simbolismo animal refleja la mentalidad medieval hacia los animales, pero también hacia los hombres porque lo más interesante de ese simbolismo sería subrayar el aspecto de la asociación entre hombres y animales, por cierto, en buena parte dominado por el miedo y los sentimientos de culpa, pero también por el control no definitivo del hombre medieval sobre la naturaleza. La proyección de las opiniones de aquellos hombres sobre sus congéneres, a través de los animales, hace que, en primera instancia, lleguemos a una deducción muy simple: los animales, por ellos mismos, interesan muy indirectamente al hombre medieval, salvo por cuestiones relacionadas con la pura supervivencia material. Esto nos llevaría a una segunda deducción: el simbolismo animal nos revela la actitud medieval ante la ciencia, al menos hasta el siglo XIII. La ciencia zoológica no interesaba grandemente, aunque el mundo animal inspire curiosidad. Los aspectos científicos del animal importan poco, pero, eso sí, reales o ficticios sirven, como en ninguna otra época histórica, para enseñar y moralizar. La simbología tendrá, pues, una clara preminencia sobre la ciencia, $y$, a través de ella, se va formando la mentalidad del hombre medieval. Gracias al estudio de la simbologia, en este caso la animal, se nos revela la propia concepción de la vida de estos siglos. Así, el hombre de esta época no distingue, o no quiere distinguir, entre lo visible y lo invisible, o dicho de otra manera, entre lo real y lo ficticio. Dominado en extremo por una concepción religiosa del mundo, sabe que el componente clave de aquella creencia es la fe, es decir, aquello que no se ve, pero que, sin embargo, existe. Ver no es necesario para creer y esto se de-

2 Actualmente estoy trabajando en un proyecto titulado "Las tres culturas zoológicas de la España Medieval»; la primera publicación salida de dicho proyecto y dedicada a la España Islámica, espero que vea la luz muy próximamente. Por lo que se refiere al tema más amplio de la Zoohistoria, ha sido defendido por mi en varias ocasiones. El trabajo general sobre sus posibilidades en nuestro campo concreto del medievalismo, fue presentado con el título "Zoohistoria: reflexiones acerca de una nueva disciplina auxiliar de la ciencia histórica" Espacio, Tiempo y Forma, Serie III, Historia Medieval, vol. 4, 367-383, Madrid, 1991. 
muestra en la tendencia verdaderamente irremediable, o el interés que demuestra el hombre medieval, por los animales fantásticos y monstruosos, que no se ven, pero que, a buen seguro existen, o al menos, existe lo que simbolizan. $Y$ seguimos remitiéndonos a lo dicho anteriormente: el mundo real es un reflejo del mundo divino, los símbolos son la clave para interpretar áquel, al que no se llega con facilidad. Se detecta, asimismo, una proclividad a fantasear la realidad: animales reales, como el caballo, aparecen coloreados de azul o de verde, porque también los colores, como tantas otras cosas, tienen su simbología.

\section{Las fuentes: Bestiarios e iconografía}

Las fuentes para el estudio de la zoohistoria simbólica medieval son fundamentalmente dos: escritas e iconográficas; en muchos casos, como en el género de los Bestiarios, dichas fuentes se encuentran indisolublemente unidas, por cuanto las ilustraciones son parte integral de las mismas, que, por cierto, han inspirado numerosos temas artísticos, de ahí que se hable con frecuencia de Bestiarios esculpidos entre los historiadores del arte ${ }^{3}$.

Dentro de las fuentes escritas, es inevitable hacer referencia al padre de los Bestiarios medievales, el famoso Fisiólogo, o mejor, Fisiologi - hubo bastantes-, compilación seudocientífica de autores clásicos sobre zoología, escrito en Alejandría entre los siglos II y Iv después de Cristo, y que permitió el floreciente citado género (Bestiarios) amén de otra literatura supuestamente zoológica. Dicha obra y sus consecuencias, son, para el tema que nos ocupa, fuente esencial ya que, a través de los animales, se ilustra el dogma y la moral cristiana. Con las Etimologias de San Isidro se redondea esa visión del mundo zoológico medieval resultado del proyecto divino.

Desde el francés de Philippe de Thaun hasta el de Richal de Fournival (Bestiario de Amor) pasando por otros tantos, este género de los Bestiarios, ha merecido estudios y análisis de especialistas, dentro de los cuales, en nuestro caso, hemos de destacar, los trabajos de Ignacio Malaxecheverria, entre otros ${ }^{4}$. Los estudios de dichos especialistas me

3 Entre los muchos trabajos de estas características destaco un clásico, el de Victor HENRI Debidour Le bestiaire sculpté du moyen Age en France. Paris, 1964. Muy recientemente Ignacio MALAXECHEVERRIA ha publicado El bestiario esculpido en Navarra, Pamplona, 1990.

4 Aunque su publicación más popular sigue siendo su Bestiario Medieval, Siruela, Madrid 1986, Ignacio MALAXECHEVERRIA ha escrito más de una docena de trabajos sobre cuestiones pun- 
permiten no insistir en las diferentes interpretaciones del género, tales como los aspectos psicológicos, antropológicos, y también, desde luego, filológicos y literarios ${ }^{5}$. Curiosamente nunca se han producido estudios zoológicos sobre los Bestiarios, a pesar de que, una parte de éstos, referidos a cada animal, consiste en el estudio de sus hábitos. Hay que adelantar aquí, aunque se ha plasmado al final de este trabajo, una muestra de cómo podría interpretarse zoológicamente algunas partes del Bestiario tomando varios animales de ejemplo, ya que las descripciones zoológicas de este género suelen ser, por las razones expresadas anteriormente, fantasiosas en su mayoría e incluso disparatadas. Hay que tener en cuenta que, además de las especies reales descritas, apenas la mitad son europeas, es decir conocidas para los hombres de aquella época. Esto puede explicar también la ingente cantidad de datos erróneos desde el punto de vista zoológico.

Las fuentes escritas sobre animales no se agotan con el género de los Bestiarios y buena parte de ellas son perfectamente adaptables para el estudio de la simbología animal. Así, los padres de la Iglesia, desde Rábano Mauro, Hugo de San Víctor, pasando por San Agustín o San Bernardo, han tratado, de una u otra forma, el tema zoológico en sus escritos ${ }^{6}$. Pero también los tratados más o menos enciclopédicos, así como otros géneros literarios, caso de los Exempla, obras maestras como el Roman de Renart ${ }^{7}$, pueden convertirse en fuente inapreciable para el estudio de la simbología animal. Advertiríamos también, como, a partir del

tuales del Bestiario. Para no hacer la lista interminable, y también para cubrir la información sobre especialistas extranjeros, me remito a la bibliografía que dicho autor ha presentado en su citado El bestiario esculpido en Navarra... pp. 315-324.

5 Sobre estos dos últimos aspectos versó la intervención del prof. Dr. D. Nicasio SalvadoR Miguel “¿Qué es un Bestiario?”, en la XI Asamblea General Ordinaria, II Sesión Científica, Zamora 12-14 de mayo 1994, SEEM. Hay que subrayar, pues, las diferencias entre las distintas fuentes escritas sobre animales a los que los profanos tienden a confundir dentro del concepto Bestiario. Aún así, las puntualizaciones filológico-literarias, no afectarían a nuestras opiniones sobre el simbolismo animal. Remitimos al lector interesado a las publicaciones de dicho especialista.

6 Siguiendo a autores paganos, Aristóteles, Plinio o Fedro, los Padres de la Iglesia escribieron abundante literatura entre los que destaca San Isidoro con sus Etimologías. Dom Pierre Miquel escribió, siguiendo sus escritos, Dictionnaire Symbolique des Animaux, París, 1992. Es destacable, asimismo, lá bibliografía moderna utilizada por dicho autor y a la que me remito, como en el caso de MALAXECHEVERRIA, por exigencias espaciales.

7 Ver Foulet, L. Le Roman de Renart, París, 1968. Ver, asimismo, los comentarios que I. MALAXECHEVERAia ha realizado del Bestiario Esculpido, en la catedral de Estrasburgo, de los funerales de Renart. Obsérvese la simbologia animal: hasta la fauna con una carga negativa tiene una lectura buena; Brun, el oso, portador del agua bendita, Ysegrin, el lobo, portador de la cruz, Tibert, el gato sostenedor del misal... tampoco es coincidencia que el celebrante de la misa fuera Brichemer, el ciervo, simbolo de Cristo. El Bestiario... Navarra... p. 38. 
siglo XIII, aquella actitud anticientífica, en donde no interesaba para nada el animal sino su versión moralizante y didáctica, va a cambiar y las fuentes zoohistóricas, desde el manual para la caza de Federico II, se adelantarán a los tratados de zoología renacentista abandonando la exégesis moral para centrarse en la observación de los hábitos animales. Tanto es asi que los Bestiarios acusan esa tendencia y se manifiestan, como en el caso de Brunetto, en donde, por ejemplo, los datos referidos a los animales conocidos, caso del topo, son zoológicamente correctísimos ${ }^{8}$. En esta misma época, se constata ese interés por los animales en las proliferaciones de las menageries o zoológicos, más propiamente Casas de fieras, afición cultivada entre muchos personajes de la época. Hasta en el arte se aprecia el cambio: si los animales plasmados en el románico responden a un criterio más o menos simbólico, en las manifestaciones del gótico, la representación del animal tiende a ser más natural.

Esto último nos lleva a enlazar con la segunda fuente para estudiar la simbologia animal, que es el arte en sus diversas vertientes, desde el mobiliario pasando por la escultura, la pintura, la orfebrería, o las miniaturas. Las posibilidades de plasmar al animal en diferentes formas son tan amplias que en un reciente libro sobre animales en el arte medieval, Janetta Rebold, describe la fauna en decenas de variedades artísticas desde el aguamanil al tapiz pasando por los capiteles ${ }^{9}$.

$\mathrm{El}$ arte medieval es una fuente fundamental para comprender, una vez más, tanto la mentalidad de la época hacia los animales como la complejidad y la ambigüedad con respecto a su representación. Desde las primeras manifestaciones paleocristianas surge una simbología estrictamente medieval basada en la interpretación de la fauna. No obstante hay que decir también que, por la forma de trabajar el artista medieval - doctrina del imitatio-, buena parte del arte animal de esta época no era necesariamente simbólico. En otras palabras, la plasmación del animal podía, responder, a veces, a criterios estrictamente decorativos. En bastantes ocasiones el animal era copiado sin más de tradiciones grecoromanas y paganas sin el menor atisbo de convertirlo en símbolo de nada. La limitación del espacio para plasmar al animal hace que no exista intencionalidad y sí condicionante material para no respetar sus formas naturales, sin que esto responda a ninguna interpretación simbólica. Se produjo también durante estos siglos un serio debate sobre la conveniencia de la imaginería

Ver Cuadro I, núm. 4 al final del trabajo.

9 The Medieval Menagerie. Animals in the Art of the Middle Ages Nueva York, 1992. 
animal sobre cuestiones de moral y dogma. San Bernardo, en concreto, defendía el aniconismo animal y no consideraba a éstos especialmente útiles como símbolos religiosos.

Sin embargo, como bien afirma Focillón, en las artes plásticas, el animal es un posible ilimitado, y el artista puede utilizar a éste con muchos fines, incluso determinados por el poco espacio que tienen para plasmarlo, como se ha dicho. Un trabajo reciente y ya citado, el de Janetta Rebold, sostiene que el artista medieval, en cualquier caso, ha sido el más adepto a inventar fauna como ningún artista a lo largo de la historia.

La realidad es que, amén de lo complejo del tema, el arte medieval, a través de la representación animal, ha dejado durante siglos una simbología arquetípica, especialmente la cristiana. Como ejemplo podemos proponer al cordero, y las diferentes posturas de aquél que representarian los diferentes aspectos de Cristo y su Iglesia. Así, el cordero ergido simbolizaría a la Iglesia triunfante, el cordero con un chorro de sangre saliendo del costado a un cáliz y sosteniendo una cruz, es el símbolo del Agnus Dei; por último, el cordero con una banderita decorada con la cruz, simbolizaría la resurrección y a Cristo redentor de los hombres.

No podemos concluir este epigrafe sobre fuentes sin referirnos someramente a una, básica para la interpretación de la simbología civil o, al menos, no necesariamente religiosa, que es la heráldica. En el campo de la simbología animal seguimos necesitando estudios específicos ${ }^{10}$.

\section{Las claves interpretativas}

Una cuestión interesante sería llegar a saber si existe una simbología animal exclusivamente medieval o si, por el contrario, detectamos una contribución a dicho simbolismo en esta época, diferenciada, es decir, con aspectos o características propias introducidas entonces.

Por esta razón conviene, en primer lugar, reflexionar sobre lo que se conserva de la antigüedad en la simbología animal, entendiendo como antigüedad la pagana, incluso la bíblica. Conviene adelantar que las conclusiones no son, en modo alguno, definitivas ya que el tema resulta suma-

10 Algunos animales, caso del toro, han recibido suficiente atención en los trabajos heráldicos. Aun asi echamos en falta trabajos de conjunto. El trabajo de Adolfo BARREDO DE VALENZUELA, "LOS animales en la Heráldica y en los Apellidos" Hidalguia, 1985, pp. 545-575, no es suficiente. 
mente complejo por la polivalencia o la contradicción detectada en las fuentes. La mejor fórmula consistiría en examinar animal por animal y seguirle, por así decirlo, una pista exhaustiva que tampoco, a mi juicio, tiene demasiado interés. En nuestro caso, resulta más operativo, por tanto, intentar sistematizar una serie de hipótesis generales, tras un análisis suficiente, de una selección de fuentes.

Una primera observación arranca de la siguiente generalización: los animales en las culturas occidentales y orientales tienen una significación tan dispar que, animales considerados maléficos o negativos en Occidente, resultan ser lo contrario en las culturas orientales. La serpiente, en Oriente, es símbolo de vida; el mono resulta, para los chinos, portador de salud, de éxito y de protección, así como de felicidad y larga vida. El cuervo, símbolo de mal agüero para los occidentales, tiene una excelente reputación para los pieles rojas americanos. El cocodrilo, símbolo de sabiduría para egipcios e hindúes, es un monstruo de maldad para los Bestiarios medievales. Otros animales, de todas formas, suelen tener un buen significado en ambas culturas. Son, pues, símbolos universales. Tal sería el caso de elefante, apreciado en Occidente y eje del universo --montura de reyes- entre los hindúes. El faisán y el gallo son igualmente positivos para los chinos y los occidentales. La abeja ejemplifica la diligencia y la obediencia tanto con indoarios como con egipcios, musulmanes y europeos. La grulla es positiva desde China hasta el mediterráneo y así podríamos continuar con sucesivos ejemplos. Otros animales, sin embargo, no superaron su asociación con el paganismo en la cultura occidental. Es el caso del jabalí, de capital importancia para los druidas celtas. Ahora bien, para el Occidente europeo de forma muy generalizada, habria que subrayar que buena parte de los animales traen una herencia de la Antigüedad, o de la Biblia, que va a pesar enormemente a la hora de su valoración. No en vano el Fisiólogo es la clave para comprender los Bestiarios y buena parte de esa información procede de fuentes grecoromanas aunque siempre existen animales, caso de lobo, que empeoraron su reputación con el tiempo. En la Antigüedad el lobo era símbolo de valor -representa a Roma no hay que olvidarlo-, pero, en los siglos medievales, exceptuando la opinión de San Francisco, el lobo es la encarnación del mal. Hay que añadir a esto que pueblos que se integrarán en la Europa cristiana, caso de los nórdicos, también tenian animadversión a los lobos, y por buenas razones. La perdiz, tan frecuente en la decoración romana, es duramente los siglos medievales, símbolo de engaño y simulación por lo que inevitablemente permanece asociada a Satanás.

Este análisis podria desarrollarse de tal forma que, para los siglos medievales, nos llevase a correspondencias o comparaciones simbóli- 
cas con otros espacios culturales coetáneos. Queda, por tanto, pendiente un estudio comparativo de la simbología de las tres culturas medievales: cristianismo, judaísmo e Islam. Las deducciones y aportaciones que se extrajeran de dicho estudio serían, sin duda, muy interesante para ahondar en las diferencias de mentalidad y cultura de dichos mundos medievales.

Volviendo al tema inicial, sólo un estudio profundo y sistematizado, del que sólo queremos aquí poner los cimientos, nos informaría sobre cuanto permanece del legado antiguo pagano o bíblico, en el mundo medieval, y en qué medida el cristianismo conserva o transforma dicho legado. En principio, el tratamiento al animal en el mundo pagano posee una característica que desaparece con el cristianismo: no existe sacralización del mismo por cuanto cualquier culto sería considerado diabólico. Sin embargo, el que muchos animales encarnen las figuras de Cristo y de la Iglesia, no deja de ser curioso, ya que, en cierta medida, se favorece, sino una sacralización, una espiritualización del animal. Otra diferencia entre la consideración de la fauna antes y después del cristianismo residiría en el hecho de que los animales, en la tradición grecoromana, tendrían un sentido más alegórico, mientras que el cristianismo los transforma en símbolos morales y religiosos. Como subraya J. Caro Baroja, el simbolismo surge cuando las religiones de la naturaleza sufren un quebranto ". En el símbolo se quiere representar, a través de una imagen, un concepto. El lenguaje simbólico quiere forzar al mundo escondido verdadero y eterno a través de actos que serian reconocibles por la divinidad. En la alegoría una cosa significa otra distinta. Los autores paganos alegorizan sobre animales - fabulistas, moralistas-; los cristianos, en cambio, más místicos, buscan una simbología en los animales, aunque ese simbolismo como hemos dicho, sea plural y ambivalente. Baste como ejemplo la propia representación de Cristo, plasmada en animales muy diferentes: el cordero y el ciervo principalmente, pero también el pez, el toro, el león. En el caso de los animales con cualidades negativas, el simbolismo cristiano sólo haría referencia, más que al conjunto del animal, a una de sus cualidades. Es el caso de la serpiente, maléfico donde los haya, cuya sagacidad la compararon nuestros antecesores medievales con una cualidad que adornaba la personalidad de Cristo.

"Sigue siendo indispensable remitirse al Diccionario de Símbolos de J.E. Cirlot, y, en concreto para nuestro tema, independientemente de los animales, a la introducción a la obra, pp. 1547. Barcelona, 1982. 


\section{ANÁLISIS COMPARATIVO DE LOS GRUPOS ZOOLÓGICOS}

Aunque al final de este trabajo se ha incluido una tabla con los animales más habituales que surgen en las fuentes medievales con sus correspondientes claves interpretativas, he querido examinar por grupos zoológicos, las principales características generales de la fauna desde su perspectiva simbólica. Por razones de espacio, y aun cuando soy consciente de que buena parte de la simbología medieval corresponde a animales fantásticos y/o monstruosos, he circunscrito mi estudio a la fauna real, comparativamente menos tratada que la ficticia ${ }^{12}$. Además también se han elegido cuatro animales sacados de los Bestiarios para analizarlos a la luz de la información zoológica e intentar explicar la razón de los datos falseados así como los sublimados, lo que constituye un tratamiento, a mi juicio, bastante original cuyas conclusiones resultan ciertamente interesantes. Dicho análisis, junto con la Tabla anterior, se halla al final del trabajo.

\section{Consideraciones generales}

Si se observa atentamente el cuadro de El Bosco «El Jardín de las Delicias" hallaremos una clave para comprender, de forma global, la significación de los animales en el mundo medieval: la representación material de los instintos. Tal idea, desde luego no necesariamente cristiana, parece válida a lo largo de los siglos medievales. Por su grado de complejidad y evolución biológica, redundando más en lo expuesto, del insecto hasta el mamífero, quedaría expresada la jerarquía de estos instintos. Los animales, en los siglos medievales, no se vieron del todo liberados de ideas muy generales sobre clasificaciones precedentes y así, existe una taxonomía animal de acuerdo con su correspondencia o pertenencia a uno de los cuatro elementos clásicos, a saber, el agua, la tierra, el aire, y el fuego. La atribución más generalizada asigna peces y anfibios al agua, reptiles a la tierra, aves al aire, y mamíferos, por su sangre caliente, al

12 Ver, recientemente traducido al español, el trabajo de Claude KAPPLER Monstres, démons et merveilles á la fin de moyen age, París, 1980. La bibliografía, sobre todo para las manifestaciones artísticas, sobre animales monstruosos y ficticios es interminable. Me vuelvo a remitir a las notas 7 y 4. Dentro de esta línea ver A. GARROSA RESINA "La tradición de animales fantásticos y monstruos en la literatura medieval española", así como N. SALVADOR MIGUEL "Animales fantásticos en La Celestina" en Diavoli e mostri in scena dal Medio Evo al Rinascimento, Viterbo, 1989, pp. 283302 . 
fuego. Dadas las limitaciones zoológicas, conscientes o inconscientes de los hombres medievales, detectamos algunos lapsus.

Por ejemplo, la ballena (mamífero) suele incluirse en la categoría de pez, en tanto que el buitre, asociado con la muerte, se relaciona con el bestiario telúrico y la salamandra, por razones no aclaradas, puesto que el animal real no tiene nada que ver con ese medio, permanece asociada al bestiario igneo.

Dentro de los estudios sobre los Bestiarios nunca, sin embargo, se ha enfocado su análisis desde un punto de vista zoológico, por cierto dificultosísima ya que se mezclan datos e historias de diferentes especies reales, más imaginarias, lo que impide una lectura biológica directa. Los análisis antropológicos, religiosos, psíquicos, filológicos etc., ponen aún más de manifiesto esta laguna sobre trabajos zoológicos del Bestiario, lo que, en primera instancia, nos llevaría a proponer una cuestión: ¿podrían determinar las costumbres y el aspecto de los animales su carácter simbólico? En caso de no ser así sería interesante comprobar cuánto de los Bestiarios constituye zoológicamente una invención y por qué. El resultado de un estudio semejante podría ampliar, con nuevas hipótesis, un campo de estudio virgen, cuyas conclusiones o aproximaciones a éstas serían de interés en campos como el de la mentalidad, vida cotidiana 0 ciencia medieval.

El animal cuya influencia en la vida social, en la economía o en la salud del hombre no es beneficioso, suele tener una nefasta consideración. Pero, en el fondo, casi todas las clasificaciones, etnológicas, etnotaxonómicas, etc., que no tengan, como la anterior, una explicación lógica, corresponden a un psiquismo elemental: el hombre es un ser enmascarado y equívoco. Por el contrario el animal no goza del don del fingimiento y tiene cualidades constantes que son lo que se denominan "manifestaciones cósmicas". A través de la significación del animal quedan al descubierto las verdaderas formas del hombre. Esta identidad subyacente hombre-animal no debe ocultar las relaciones hombre-animal durante los siglos medievales: no sabemos si eran tan fraternales como afirma algún autor, o sí, en realidad, eran antagónicas, dominadas por el temor a una naturaleza indómita y amenazante.

En simbolismo, para interpretar correctamente al animal, es necesario respetar la gradación jerárquica o la distribución espacial así como saber que las agrupaciones animales, las luchas o los animales contrapuestos - sean iguales o diferentes - tendrán valores simbólicos distintos. Por ejemplo, los animales en bandadas suelen asociarse a plagas o catástrofes. Recuérdese - dando un salto cronológico muy grande- la famosa 
película de Hitchcock, Los pájaros. Es particularmente interesante la colocación del animal para la ciencia heráldica, tan peculiarmente medieval, pero ineludible, como hemos dicho antes, como fuente de la simbología medieval, civil, también para los animales ${ }^{13}$.

Todas las culturas tienen sus animales emblemáticos favoritos. En Roma por ejemplo, destacan el águila, el jabalí, o el lobo, pero también el caballo y el león. La Edad Media heredó sólo en parte estas especies para la simbología civil o militar, de nuevo nos remitimos a la ciencia heráldica, a lo que contribuyó la sociedad feudal con sus valores guerreros. Los siglos medievales tuvieron, no obstante, una simbología arquetípica bien conocida y dominada por el hecho cristiano. Así desde los sarcófagos paleocristianos, en donde hallamos plasmados los pavos reales, pasando por los gallos y las grullas, llegariamos al simbolismo mayor del palomo, el cordero y el pez. Sin olvidar, naturalmente, a los animales de los evangelistas, difundidos una y mil veces, a saber, el águila, el toro, y el león, símbolos, además, especialmente el primero y el último, heráldicos por excelencia.

\section{El primer grupo: de los arácnidos a los reptiles}

Este grupo es simbólicamente homogéneo puesto que dentro de él tenemos a los animales considerados más primitivos. Esto hace que subyazca un cierto resentimiento de rechazo hacia faunas que no se conocen bien, $y$, que no son especialmente familiares, pero que se arrastran, reptan y se asocian con plagas que perjudican al hombre.

La araña, por lo general, tiene una simbología más bien nefasta: es traicionera e hipócrita; sin duda esto se debe a su forma de cazar al acecho y con trampas, pero los comentaristas cristianos extraen algunas lec-

13 Existirian clasificaciones de animales que coinciden con la propia historia evolutiva del animal. Hay clasificaciones de fauna lunar y solar con todo lo que esto lleva consigo de asociaciones morales-bueno o malo/luz y tinieblas. En cuanto a las cualidades atribuidas al animal, para interpretarlas correctamente, existen alusiones, fantásticas naturalmente, que nos harian remontarnos a esa edad de oro anterior al intelecto del hombre en que las fuerzas ciegas de la naturaleza, sin estar sometidas al logos, poseian condiciones extraordinarias, como hablar. Existen tradiciones hebreas e islámicas que nos describen animales parlantes. También, dentro de las contraposiciones, la plasmación de dos animales -iguales o diferentes - simbolizarian el equilibrio; en alquimia, dos de la misma especie y distinto sexo significaria contraposición de elementos, etc. Para Heráldica y, en concreto simbolismo, animal ver los capitulos 8 y siguientes de Pedro José de Aldazával y Murguia Compendio Heráldico, arte de escudos de Armas según el methodo más arreglado del Blasón y autores españoles. Pamplona, 1773. 
ciones positivas de la misma utilizando la relación con la telaraña para ilustrar su capacidad creadora, diligencia, paciencia etc. Sin remisión es el significado de otro arácnido, el escorpión, que, en el simbolismo cristiano, representa al pueblo judío. Otro animal tan aparentemente elemental como la esponja, ejemplificará la capacidad para absorber, no ya el agua circundante, sino el mensaje divino. Moluscos y crustáceos, muy poco habituales en los tratados medievales, tienen, sin embargo, una simbologia muy clara: no es difícil deducir la gran significación que tiene la concha, asociada, desde siempre, con el peregrino - de ahí que exista una especie zoológica denominada así. En los Bestiarios la vieira resulta una locura biológica al mezclarse cantidad de datos de otras especies. Otro ejemplo, la ostra, es símbolo de la Encarnación, siendo la perla la Virgen María. El cangrejo, el crustáceo más familiar para el pueblo, representaba al pecador por su peculiar forma de andar, tanto hacia adelante como hacia atrás, como el alma que avanza y retrocede en su lucha contra el pecado.

El grupo de los insectos, no gozaba, globalmente, de mala reputación, seguramente por su adscripción al elemento aire, volátil, que significa trascendencia y elevación, y, por lo tanto, espiritualidad. No obstante la clasificación de los insectos más habituales en la simbología medieval podría corresponder a la tradicional de benéficos y maléficos que nuestros antiguos textos de bachillerato recogían en sus páginas. Hormigas, avispas, pulgas, y langostas son perjudiciales y también, en general, negativas. Gusanos de seda, mariposas, abejas, etc., son positivas y benéficas. Quizás sea la mariposa la que goza de mejor reputación -trascendente y espiritual- alegórica de la luz del alma. La abeja, laboriosa y obediente, heredaba una tradicional buena fama, que le venía de Oriente. Las Iangostas, como es lógico, no consiguen desembarazarse de su condición de plagas bíblicas o de las terribles referencias contenidas en el Apocalipsis. No hay que olvidar que las plagas de estos insectos eran frecuentes en los siglos medievales con sus secuelas - destrucción de cosechas- de hambre y miseria. Hay algunos insectos antitéticos (bueno/malo) caso de la abeja/avispa, como después comprobaremos con otras especies. Incluso los insectos considerados malignos pueden tener aigún defensor. Tal sería el caso de la cigala asociada a la leyenda franciscana, o de las hormigas, en la tradición no cristiana portadoras del don de la adivinación, ejemplo de previsión y actividad.

Los reptiles, por último, no suelen quedar bien parados. A pesar de ello, el camaleón y el lagarto, a través de sus inventadas costumbres en los Bestiarios, sirven, especialmente el último, para aleccionar sobre la luz, el sol, que es Cristo. Los reptiles, se arrastran, reptan sinuosamente, lo que no ofrece excesiva confianza y, además, muestran su lengua bífida, 
0 , lo que es peor, mudan de piel, signo de inconstancia. Casi ninguno goza de especial devoción. Pésima reputación tiene el cocodrilo, malo y curioso, hipócrita -lágrimas tras devorar a sus víctimas, otra exageración- animal inexistente en la Europa medieval lo que hace que los Bestiarios fantaseen con su iconografía y lo asocien al dragón en muchas ocasiones. Quien naturalmente se lleva la palma en el campo de la antipatía es la serpiente, la cual, por sus connotaciones bíblicas, es una de las simbologías más frecuentes del diablo. A pesar de ello, y de modo excepcional, algunas de las cualidades del ofidio merecen su comparación con Cristo, por ejemplo, la astucia. También se conservan representaciones iconográficas relacionándola con San Juan Evangelista. Las víboras, no tienen, ni por asomo, una lectura buena: como en el caso de los escorpiones son comparadas sistemáticamente con los judios, los felones. No podemos concluir sin olvidar a la salamandra, cuyas costumbres, todas inventadas en los Bestiarios, la convierten en portadora de una simbologia francamente positiva.

\section{Anfibios y Peces}

Agrupados juntos por su adscripción al medio acuático, en ambos casos nos encontramos con una característica común en estos animales: son mayoritariamente casos de simbología positiva frente a la negativa. Los dos anfibios más comunmente citados y representados en las fuentes son las ranas y los sapos. Por cierto, la dualidad es antitética, como en el citado caso avispa/abeja. En el tandem rana/sapo, el segundo sería una degradación de la primera. Al sapo, como a la serpiente y al cocodrilo, se les asocia, en ocasiones, con animales inexistentes, monstruosos o fantásticos caso del basilisco o del dragón, con toda la carga negativa que esta conlleva. En las manifestaciones iconográficas, de las bocas de los pecadores suelen salir sapos. Las ranas, sin embargo, gozaban, como benefactoras de cultivos, de una situación privilegiada en los templos: las pilas del agua bendita.

Por lo que se refiere a los peces, símbolo de Jesús por excelencia, mantendrán, en el cristianismo, por su herencia de otras culturas, su muy buena reputación. Animales psíquicos o sagrados, los peces, sin embargo, han conocido otras lecturas: interpretaciones sexuales por su forma fálica. Las sagradas escrituras los citan en varias ocasiones, siendo posiblemente la referencia más significativa la del milagro de la multiplicación de los panes y los peces. Son también, los peces, símbolo de la fecundidad por la cantidad de huevos producidos. Los hombres medievales, cuyos cono- 
cimientos ictiológicos eran bastante limitados, consideraban a la ballena como un pez, probablemente en función de sus antecedentes bíblicos, aunque esta tuvo una reputación cambiante e incluso positiva en los Bestiarios, que mejora su herencia del pasado. No hay que olvidar que la caza de las ballenas fue, localmente, un importante recurso para muchas poblaciones costeras europeas, de ahí el posible cambio de connotación. La rémora era la representación de Nuestro Señor Jesucristo, y el delfín también aparece como un claro signo cristiano. Si bien existe más proclividad por los peces pequeños, casi todos ellos parecen haber gozado de buena reputación en el mundo medieval de los símbolos.

\section{Aves}

Si observamos el cuadro de Ambroggio Lorenzetti «La Virgen del Niño", nos hallamos ante la forma más habitual de la simbología de las aves. En efecto, el Niño Jesús sostiene en sus manos un pájaro, símbolo de la resurrección.

Adscritas al elemento aire, las aves, casi siempre representan la trascendencia en el plano teórico, así como también la espiritualidad. Con harta frecuencia las aves representan, asimismo, a las almas y así habría que interpretar el cuadro de Giotto que plasma a San Francisco de Asís -independientemente de las connotaciones de fraternidad zoológicapredicando a las aves. Existen otras lecturas, menos positivas, de la simbología de los pájaros: las referencias bíblicas identifican a éstos con los pensamientos inoportunos y no hay que olvidar como, en el evangelio, son ellos los que se comen la simiente en la parábola de los sembradores. No todas las aves, desde luego, gozaron de la misma significación. Odón de Túsculo acomodó una clasificación comparativa de esta fauna con los hombres: los sencillos serían como las palomas, los astutos como la perdiz, los confiados como el halcón, los cobardes como la gallina, los sociables como las golondrinas y los que buscan la soledad, como la tórtola. Según su vuelo, alto o bajo, representarían las aves una actitud terrena o una pasión espiritual. Según fueran nocturnas o diurnas nos encontraríamos con un significado añadido. Si de forma enormemente simplista dividiéramos las aves en buenas y malas, dentro del primer grupo hallaríamos al aguila, la cigüeña, el gallo, la garza, la grulla, el pavo, el pelícano, la golondrina e, incluso, al cisne. Dentro del segundo grupo estarían insertas, por contra, el buitre, el cuervo, la perdiz, la lechuza, y más o menos, todas las aves de rapiña. Existen, como en otros grupos zoológicos, e incluso con más frecuencia, dualidades antitéticas: buho/lechuza; codorniz/perdiz; 
milano/buitre, etc. Bastantes aves están asociadas con animales inferiores. Quizás sea el caso más frecuente el del águila y la serpiente, pero otras como el pelícano y la cigüeña también se relacionan con dicho reptil, significando el triunfo del bien sobre el mal. Esto es así porque, lógicamente, se establece enemistad con el demonio, representado por la serpiente. En heráldica la asociación es frecuentísima.

Algunas aves son más complejas y polivalentes que otras. Es el caso del cisne -adscrito al elemento agua, como ya dijimos- o del avestruz que supera, por lo general, durante los siglos medievales su pésima reputación de negligente, glotón e hipócrita -por su comportamiento con los huevos-y acabará por ser una alegoría de la justicia.

Por último, algunas aves son símbolos cristianos por excelencia, caso de la paloma, el pelícano, la tórtola, -fidelidad y castidad- así como el pavo real.

\section{Mamiferos}

Este grupo resulta el más difícil de sistematizar al ser, además, el más numeroso. En principio podríamos dividir a los mamíferos en hervíboros y carnivoros. Por lo general, los primeros gozarían de una simbología más positiva que los segundos. Dentro de aquel grupo nos encontramos símbolos cristianos por antonomasia, caso del ya citado cordero, o del ciervo, quizás uno de los más bellos, y, por supuesto, las ovejas, símbolo de los justos. También hay herviboros con peor reputación, caso de la cabra -aún cuando Casiodoro logra revalorizarla-, comparando algunas de sus cualidades con las de Cristo. Con diferencia, el peor parado es el macho cabrio, símbolo inequívoco del diablo que no tiene nada que envidiar a la serpiente. Asno y camello tienen una simbología bastante compleja y polivalente. Por lo que se refiere al toro, a pesar de una posición de prestigio en las esculturas de la catedral de León, suele infundir bastantes sospechas paganas por lo que su valoración, en general, es más bien negativa, y más aún si es negro. La antítesis del toro es, naturalmente, el buey símbolo del evangelista San Mateo. El caballo, apreciadísimo en la Edad Media, debe superar, y lo hace gracias a los valores de la sociedad feudal, una simbología adversa que arranca de la Biblia, que no de la antigüedad pagana. Así la herencia del caballo a comienzo de la época medieval era más bien sospechosa y severa. Los caballos de la Apocalipsis eran una fijación habitual. Aun así superará con creces dicha reputación para convertirise en símbolo de nobleza y orgullo. Un animal, también herviboro, cuya carga simbólica y alegórica es compartida por buena parte de 
las culturas es el elefante aun cuando sus cualidades zoológicas, según los Bestiarios, sean en buena parte invenciones en aras de la enseñanza dogmática del cristianismo. Por último, los pequeños hervíboros, como la liebre, gozan de una bellísima reputación como alegoría de la fertilidad, y también de la virginidad -los conceptos no son excluyentes. Por dichas razones, se las representa a los pies de las doncellas.

Entre los carnívoros los felinos gozan de una simbología ambivalente. Naturalmente, tendriamos en primer lugar, como en el caso del elefante, un clásico de la simbología, universal: el león, positivo en alto porcentaje, si bien existen segundas lecturas con alguna carga negativa que degradan ligeramente la valoración muy alta del animal. Otro felino ciertamente ensalzado en los Bestiarios es la pantera, asociada a la Casa de Judá en los relatos bíblicos, y como en el ejemplo anterior, símbolo también de Cristo. La pantera, apreciada por su belleza, es también valorada, en los Bestiarios, por su aliento que emite una fragancia maravillosa. Esto último, naturalmente, es pura ficción, lo que no ha impedido asociaciones muy recientes. El perfumista y joyero Cartier presentó hace poco tiempo una fragancia denominada Panthere. Ambos casos -león y pantera- se oponen al del tigre, de pésima reputación. El zorro, el lobo y el oso-animales heráldicos por excelencia, signos muy "civilistas" - no consiguen cristianizar su simbología. El primero resulta ser la encarnación de Satán, y los tres son tildados de crueldad y primitivismo, añadiéndose la pereza en el caso del oso, sin duda por sus hábitos hibernantes. No obstante la literatura o la visión franciscana de la naturaleza tiende a suavizarles. No es el caso del jabalí - voraz y lujurioso-y, por extensión, del cerdo. Para el primer caso, no obstante, la intrepidez y el arrojo, le hacen merecedor de algunos elogios. El perro, símbolo de la fidelidad y de la amistad desde la tradición pagana, al igual que el caballo, tiene algunas referencias bíblicas adversas, lo que no impide que, junto con el noble bruto, se transforme en el simbolo arquetípico de la sociedad feudal. Noble y fiel seguirá a sus amos hasta el sepulcro en donde le acompañará, como buen vasallo a su señor, a sus pies. El gato, por contra, sigue asociándose con la traición. Ejemplificará al hereje, y, en las muchas versiones de la Última Cena, no faltará el felino pegado también a los pies, en este caso, de Judas.

Los pequeños mamíferos, caso del topo, el erizo -sus espinas son los pecados humanos - no gozan de una simbología positiva. El primero es un símbolo herético, figura del diablo. Hay que recordar que, además, este pequeño animal era una plaga para muchos cultivos y era, por ello, muy bien conocido en Europa. Algo parecido le pasa a la rata, verdadero azote para el hombre medieval -recuérdese como transmisora de la peste negra- Sin embargo, los murciélagos, beneficiosos para la agri- 
cultura por sus hábitos insectívoros, no gozan tampoco de buen cartel. Es claro que su aspecto y más aún su nocturnidad - también ocasionalmente son transmisores de la rabia- no les hacian muy agradables.

Finalmente, el que tiene más similitudes zoológicas con el hombre, y asi lo hacen saber los Bestiarios, el mono, es básicamente negativo, si bien sus supuestas costumbres ejemplifican la vida del pecador. Hay mamíferos que se les considera como animales fantásticos o inexistentes, caso del rinoceronte - conocido en Europa desde 1498- y asociado, por su cuerno, al unicornio, o del hipopótamo, llamado caballo fluvial y denominado pez. La ignorancia zoológica hace que muchos disparates, en realidad, respondan a una característica posible de razonar; tal es el caso de la hiena, tildada de hermafrodita - es masculina y negativa con toda la carga negativa que eso conlleva- que sólo responde a una peculiaridad muy evidente: los genitales, tanto del macho como de la hembra, son del mismo tamaño y apariencia.

\section{CONCLUSIONES}

Durante los siglos medievales, en el Occidente, los hábitos zoológicos podían estar al alcance de cualquier observador imparcial. Sin embargo, no interesaban. Es más, la mayor parte de los Bestiarios fijan su atención en especies no europeas. La realidad del mundo animal era perfectamente secundaria, salvo por razones obvias de utilidad y supervivencia, ya que los intereses científicos se veían claramente eclipsados por las necesidades de la fe cristiana. Hay excepciones, naturalmente, a esta regla, y existieron verdaderos precursores de científicos tan empiristas como siglos después, caso de San Alberto Magno que escribía sobre el avestruz, contraviniendo todo lo afirmado por los escritos de la época: "Se dice de esta ave que come el hierro y lo digiere pero yo no lo he comprobado, pues habiendo ofrecido hierro a varios avestruces, no quisieron comerlo". Salvando casos como éste, los animales, con toda su carga simbólica polivalente, servían perfectamente a los planes divinos y ejemplificaban la moral y el dogma. Algunos de aquellos animales, los "cristianos" por excelencia, eran, al cien por cien buenos, pero todos, desde el gusano hasta el elefante, gozan de un símbolo. Ninguna otra sociedad en la historia se ha ocupado de otorgar a los animales un papel tan sistematizado a través de un género, Los Bestiarios, que, si bien tiene antecedentes, resulta único, por la homogeneidad de su objetivo en la cultura medieval europea. Aunque sabemos que existen unas transferencias procedentes de la Antigüedad, los animales y sus mensajes en la cultura medieval son el re- 
flejo de la voluntad divina, sean estos animales naturales o fantásticos. Por eso no estoy de acuerdo con las afirmaciones de autores que haban del reino animal, en esta época, con un simbolismo negativo, ejemplificando el mundo del mal. Dominados por la religión, los hombres medievales convirtieron a los animales en símbolos del bien y del mal, pero incluso en el último caso, había esperanza de salvación, como para el hombre, siempre existía alguna cualidad positiva que redimía al animal, en una interpretación ciertamente antropomórfica.

¿Qué perdura hoy de ese legado medieval en el simbolismo animal? Es perfectamente ocioso entrar en la polémica de si ese legado cultural sólo afectaba a las capas más altas de la sociedad ya que ellas mismas se encargaban de que, por las razones antes explicadas, tuviera influencia en el pueblo. Otra cuestión muy distinta es que las clases populares supieran a que respondía toda esa carga simbólica desde un punto de vista erudito. Además, a más abundamiento, buena parte de lo descrito en las fuentes escritas podían ser proporcionadas por individuos cuya relación con el animal era bien evidente: pescadores, ganaderos, cazadores, etc. Hay autores que sostienen -R. Delort, p. e.- que la concepción medieval del animal se ha perpetuado a través de la tradición oral, del folklore y de cientos de manifestaciones artísticas. ¿Qué son, si no, los refranes, por decir un ejemplo, dentro de la cultura popular? gracias a ellos comprobamos toda la carga simbólica mantenida a lo largo del tiempo. A través de la simbología animal, el hombre quiso llegar a captar una realidad superior y sagrada: los animales y su significación eran un código mágico reflejo de una voluntad divina. Es muy posible que el legado de la simbología mística animal aun perdure como una aportación más de los siglos medievales 14. Nuestros conocimientos zoológicos han crecido a lo largo del tiempo, pero el símbolo es tan fuerte que nos persigue. Por ello seguimos diciendo que se tiene vista de lince, y se lloran lágrimas de cocodrilo. Por eso también la serpiente ha dejado de asociarse al Diablo - en el cual hasta los más creyentes se resisten a aceptar- pero no ha dejado de relacionarse con el mal ${ }^{15}$. Y por la misma razón la paloma sigue siendo, para los cristianos, el símbolo del Espíritu Santo, y para el resto de los hombres, el de la paz.

14 Robert Delort, Les Animaux ont une histoire, París, 1984. Ver especialmente la pp. 74 y ss.

15 Volviendo a la afirmación sobre la segura "redención" de los animales, incluso en los de peor reputación observamos la mano divina: la serpiente, excepcional, podia representar a Cristo, y la cuestión era tan compleja que, para saber cuando representaba al Señor o a Satanás, debian de reunirse, según Rábano MaURo, los Padres de la Iglesia para pronunciarse sobre ello. 


\section{Cuadro 1}

Análisis zoológico de cuatro ejemplos según la información habitual contenida en los Bestiarios *

\section{EL BUITRE}

Datos verdaderos: "Mora en lugares elevados y abiertos, anida en las rocas o en una grieta de las montañas... no vuela con rapidez debido al tamaño de su cuerpo... Ven desde mucha altura... muchas cosas que nos ocultan las montañas" (elemental).

Datos falsos, razones para explicarlos: "El buitre es más voraz que todas las demás aves. Ayuna durante 40 días y, cuando encuentra alimento, come 40 medidas y asi se prepara de nuevo para el ayuno de 40 días". La asociación del ayuno y del número cuarenta es bastante sencillo de interpretar según citas evangélicas: Cristo ayunó cuarenta días en el desierto. Es bien cierto que el buitre ayuna, no exactamente cuarenta días, claro. La razón para explicar este proceder es que la aparición de carroña es impredecible. Cuando aparece, lo mejor es intentar saciarse y dicha estrategia la realiza cualquier carroñero, sea buitre, chacal, hiena o marabú.

"Los buitres, como las águilas, divisan los cadáveres incluso cuando se encuentran más allá de los mares". Los buitres se guían por otros buitres. Cuando uno descubre un cadáver se lanza hacia él y los otros buitres más cercanos a él lo siguen, iniciando una "asociación en cadena" que puede abarcar hasta $100 \mathrm{~km}$., de distancia.

"Los buitres no copulan». Es difícil de observar sus costumbres de anidamiento.

«El buitre tiene tan buen olfato que huele la carroña a mucha distancia". Es radicalmente falso: el animal no tiene buen olfato, sin embargo la razón para explicar ese comentario nos remite a lo dicho en líneas precedentes: la localización de cadáveres - visual-y el proceso de asociación en cadena se produce habitualmente.

"Está acostumbrado a predecir la muerte de los hombres..." Siempre que hay cadáveres en campo abierto el buitre aparece con prontitud porque las posibilidades de que haya alimento cerca son muy grandes.

* Este cuadro no hubiera podido escribirse sin la ayuda de un zoólogo. Agradezco al protesor Dr. Arturo Morales MuÑiz su asesoramiento en el análisis de los datos contenidos en los Bestiarios. 
"La propiedad del buitre es que, cuando un ejército se desplaza, él va en la misma dirección porque espera encontrar algunos cadáveres para comérselos". No es verdad. Los buitres son frecuentes en zonas cálidas con campos o bosques abiertos, independientemente de que circulen por ellos ejércitos o no. Sin embargo, las concentraciones de animales desplazándose por tierra suelen atraerles. Instintivamente saben que puede haber alimento a la vista.

Datos sublimados: "Las hembras conciben sin ayuda de los machos... ¿Cómo podemos entonces dudar de la Virginidad de María...?»

"Por el buitre se entiende el diablo, que sabe siempre qué hombres van a cometer maldades..." (La carroña, evidentemente, es asociada al hombre malo).

«Este buitre, que tiene tan buen olfato y sigue gustosamente a las tropas podemos compararlo a todos aquellos que van gustosos allá donde sienten que habla un hornbre (prudente) o donde se muestra la auténtica sabiduría". (En esta ocasión la interpretación de los desplazamientos del animal se enfoca desde un punto de vista positivo).

Nota:

Los buitres sólo habitan en países cálidos, donde existen corrientes térmicas de aire ascendente que permiten sus planeos prolongados. Hablamos de tierras mediterráneas, africanas y del Próximo Oriente. En principio, por tanto, las exégesis deberian ser bizantinas, musulmanas, judias, romanas... en los Bestiarios europeos, sensu stricto, franceses/alemanes, al buitre sólo podían conocerlo indirectamente, puesto que salvo en los Alpes y en el Mediodía francés, es animal infrecuente.

\section{EL AVESTRUZ}

Datos verdaderos: «Es un ave que no está hecha para el vuelo... tiene dos alas pero no puede volar", "... cava un agüjero en la tierra, en el que pone los huevos... es ave de muchísima fuerza... tiene el cuello largo, como un cisne y cabeza igual, sólo que es plana por encima... patas de asno... y los pies hendidos, como los del ciervo" (elemental, es un ave corredora).

Datos falseados, razones para explicarlos: "...cubre los huevos con arena y, como es perezosa, no vuelve a ocuparse de ellos. Los pone en verano de forma que el sol ardiente pueda hacer lo que debería por ella 
misma...". Durante el día el calor sirve de incubadora natural y el ave puede dedicarse a otros menesteres. Los avestruces incuban de noche para que no se enfríen los huevos. Los días nublados, por ejemplo, si que incuban.

"Se traga hasta el hierro al rojo vivo, clavos y carbón ardiente y que todo eso sienta muy bien a su estómago". Las aves ingieren piedrecitas para almacenar en su molleja a fin de ayudar en la trituración de alimentos. Cuanto mayor el ave, mayor el tamaño de las piedras $u$ objetos. De ahí la leyenda de que traguen clavos, que, por cierto, podría ser cierto y realizarlo sin problemas en un caso de despiste.

"Arrebata a los elefantes jóvenes del lado de su madre..." Podría enlazar con el dato, verdadero, sobre su enorme fuerza (?).

"Dios la ha hecho estúpida... abandona sus huevos sobre la tierra desnuda, en medio del camino, donde los pisotean y los rompen y esto está dispuesto así para que no se multipliquen y se conviertan en un peligro para el hombre". Al ser un ave terrestre, no voladora, no tiene opción de poner los huevos en otro sitio que no sea el suelo.

"Es dura para con sus pequeños como si no fueran suyos". Es un comentario, como tantos, zoológicamente hablando, gratuito.

"Sabed que su estómago es su garganta, donde retiene sus alimentos". La información proporcionada confunde la molleja -parte anterior muscular del estómago de todas las aves - con la garganta, ya que se sitúa entre esta y el auténtico estómago (posterior) glandular de toda ave. "Cuida los huevos de algún otro pájaro". Es un comentario, seguramente, compensatorio por haber abandonado sus huevos como afirman... ¿pensarían que debía incubar algo diferente?

Datos sublimados: "El hipócrita no se cuida de sus pequeños, porque se ama a sí mismo y se aferra por las cosas exteriores". Partiendo de datos incompletos y falsos, se utilizan costumbres supuestas del animal para moralizar. "Representa al hombre que vive en caridad y que es paciente, humilde, sufrido y piadoso". Esto debe derivar de que el huevo es calentado pasivamente por el sol, sol de la justicia.

«El avestruz en el desierto es la simulación del converso. El Señor dice que será glorificado por el dragón y el avestruz, porque con frecuencia lleva a los que son abiertamente malos y pretendidamente buenos a convertirse en sus servidores en el fondo de su pensamiento..."

"Dios es el avestruz..., los polluelos, la gente...». 


\section{EL ELEFANTE}

Datos verdaderos: "Con su nariz se lleva a la boca las hojas que come parece una serpiente... poseen gran inteligencia y memoria; se desplazan en rebaños... la gestación dura dos años... paren una sola cría... se preocupan en gran manera de sus bajas, conduciendo a los heridos y agotados al centro del rebaño".

Datos falseados, razones para explicarlos: "Carece de deseo de copular». La cópula es muy corta y silenciosa. "Viven trescientos años". Son muy longevos, pueden vivir hasta cincuenta años. "Su naturaleza es tal, que si cae al suelo, no es capaz de incorporarse". El enorme tamaño hace que en determinados tipos de caídas, por ej.: de costado, les resulte imposible incorporarse a menos que puedan apoyarse o recibir ayuda de otros compañeros. "Carece de articulaciones en las rodillas". Las patas son columnares, no dobladas como la mayoria de los mamíferos cuadrúpedos. "Al caer pide auxilio... e inmediatamente aparece un gran elefante... aparecen doce elefantes... ni siquiera ellos pueden alzar al caído... y llega enseguida un elefante muy pequeño que coloca su boca y su trompa bajo el caído, levantándolo". (El elefante grande es la Ley mosaica, el pequeño es Cristo). El elefante, en realidad, es una especie cooperativa que ayuda y pide ayuda a los miembros de su rebaño. "No existen animales mayores". Deberían de haber añadido en tierra, ya que las ballenas son mucho mayores. Los datos sobre la mandrágora, y la concepción son absolutamente falsos, "...copulan dándose la espalda", no es cierto. El pene larguísimo del animal, hasta un metro, ¿podría dar origen a esta fantasía? "Los ratones le asustan", falso absolutamente.

Datos sublimados: "El elefante y su hembra representan a Adán y Eva" (antes de la caída, naturalmente). Enlaza con la "inexistencia» del deseo de copular, interpretado como virtud. Nos remitimos a los datos sobre la cópuia.

"Y cuando están en combate, sólo utilizan uno de sus colmillos, y guardan el otro por si lo necesitan; sin embargo, cuando van a ser vencidos, se esfuerzan por utilizar los dos.». Es una deducción falsa, pero los colmillos son asimétricos en los más grandes, por lo que durante cualquier contacto uno de ellos alcanza y penetra antes en el objetivo. «...la sangre de este (el elefante) es fría...". La sangre en superficie expulsa calor por lo que es más fría que la del interior del cuerpo". "Cuando el elefante lucha con el unicornio, le presenta la espalda, y no el vientre". Elemental, en lucha con cualquiera se presentaría la piel del lomo que es más dura que la del vientre. "Por naturaleza los elefantes son bondadosos y no tienen 
hiel..." Son tranquilos, la talla grande ralentiza la fisiología y el animal parece vivir a ritmo más pausado.

\section{EL TOPO}

Datos verdaderos: "Siempre excava en el suelo y se lleva la tierra" (vive en galerías). "Se traga las raíces por debajo de los frutos" (no sólo las raíces también los tubérculos y hasta el tallo de las plantas). "Es una de las bestias del mundo que oye con mayor claridad" (tiene un oído finísimo para compensar la ausencia de visión; adaptación normal en una especie fosora). "Animalillo de rabo mocho". "El topo es un animalito que camina siempre bajo la tierra y cava en diversos lugares, y come las raíces que encuentra, aunque la mayoria de las gentes diga que vive solamente de tierra. $Y$ habéis de saber que el topo no ve nada, pues la naturaleza no quiso abrir la piel que tiene sobre los ojos; y así, no le sirven para nada, puesto que no están descubiertos" (Perfecto).

Datos falseados, razones para explicarlos: «Degrada la tierra en la que vive, estropeándose las hierbas". No degrada la tierra pero come partes vitales de las plantas que acaban por morir y, además, el suelo muy removido hace que otras plantas se echen a perder. Esta deducción, aunque errónea, es lógica y comprensible. "Carece de ojos"; están atrofiados y apenas visibles bajo la pelambrera. "El topo vive de tierra pura». De lo que vive es de los animales y plantas que encuentra en las galerias que cava. "Tiene tan buen juicio que coge para mantenerse lo que necesita tomar». El alimento, por norma, no suele abundar. Todos los animales procuran comer lo que hay, en el momento que lo encuentran.

Datos sublimados: "Es una figura del diablo que estropea todos los lugares en los que mora". Derivación de las observaciones erróneas citadas anteriormente. "No hay hombre que pueda pecar tan silenciosamente que no se le oiga". Derivación de una observación cierta, el magnífico oído del animal. "No es capaz de reconocer a los justos", supuesta mala vista, en realidad, es ciego. "Es uno de los cuatro animales que viven de puros elementos». 


\section{Cuadro II}

\section{Interpretación simbólica de los Animales *}

Influencia Calificación Significación ${ }^{1}$

$\begin{array}{llll}\text { 1. Abeja } & \text { ratificada } & \text { positiva } & \text { Obediencia } \\ \text { 2. Águila } & \text { idem. } & \text { positiva } & \text { Poder/CRISTO } \\ \text { 3. Araña } & \text { idem. } & \text { ambivalente/negativa } & \text { Hipocresia/regeneración } \\ \text { 4. Asno } & \text { dudosa/involución } & \text { compleja/negativa } & \text { Cobardia/Humildad } \\ \text { 5. Avestruz } & \text { superación } & \text { polivalente } & \text { Negligencia/Justicia } \\ \text { 6. Ballena } & \text { superación } & \text { polivalente } & \text { El Mundo }\end{array}$

* En este cuadro se contemplan tres cuestiones puntuales con todas las limitaciones que llevan consigo. Se trata de un enfoque general en donde las excepciones no se advierten. Dado que en texto hemos hecho referencia expresa a la mayoría de los animales aquí incluidos, en esta ocasión lo hemos esquematizado lo más posible.

En la Influencia, se contempla la tradición simbólica animal y/o alegórica de los animales en el mundo pagano grecoromano y también biblico. Ratificada, significa que, salvo excepción, dicho pasado simbólico se confirma. Superación quiere decir que el animal ha superado su calificación. Involución es, lógicamente, to contrario, en algún caso he añadido a este concepto dudosa.

Por lo que se refiere a la Calificación, las opciones son básicamente dos: negativa/positiva aun sabiendo que la mayoría de los símbolos animales son polisémicos, esto es, polivalentes. Cuando dicha polivalencia impide saber que se inclina hacia un lado u otro, sólo constará dicha palabra. Excepcionalmente hay animales duales, o perfectos.

1 La Significación es 10 más arriesgado del cuadro ya que se trata de elegir el símbolo más habitual del animal, y ya hemos comentado, que suele ser polivalente. Por ello escribimos una o dos cualidades, utilizando la información de los Bestiarios y las otras fuentes descritas en el trabajo. No obstante advierto que dichas cualidades, simbolos etc., están sesgados hacia la interpretación cristiana por razones obvias. Sin embargo las mismas cualidades pueden perfectamente asociarse a simbolismo «civil». Me explico. En Heráldica, generalmente, se utilizan los símbolos animales con sus cualidades religiosas aplicadas, en esta ocasión, a los valores guerreros y caballerescos de la sociedad feudal. Por ej.: si la salamandra significa pureza — desde un punto de vista religioso--, su transcripción, civil, seria purificación del honor. El delfín es simbolo del amor de un principe a sus vasalios. El elefante, en su lectura civica, significa majestad (de ahí que no doble la rodilla). El carnero, victima sacrificial, en este caso simbolizaria a reyes y generales que han de sacrificarse (Toisón de Oro) por sus súbditos. La tortuga, cuyo valor mistico (contemplación, retiro) es innegable ejemplifica los valores guerreros de la prudencla y sagacidad (se retira en su caparazón- cuando es mejor no hacer frente al adversario). El pelícano es el símbolo de un señor que se sacrifica por sus vasallos - tema de abrirse el pecho y alimentar con su sangre a los polluelos - esta vez en versión no religiosa. Pero lo que es más importante para la simbología cívicá frente a la religiosa es su capacidad para reciclar animales ciertamente de mala reputación en su lectura espiritual. El honor, la prudencia, la astucia, la disciplina, el arrojo, la vigilancia, etc., todos los valores guerreros, incluyendo lógicamente la fidelidad y la lealtad, mejoran básicamente a animales dudosos, y redimen definitivamente, a los condenados. He aqui algunos ejemplos: la zorra se contempla como un general valeroso, la cabra derrocha arrojo en servicio del rey y de la 


\begin{tabular}{|c|c|c|c|}
\hline 7. Buey & ratificada & positiva & Paciencia \\
\hline 8. Buho & dudosa/involución? & polivalente & Vigilancia/Pecador \\
\hline 9. Buitre & idem. & ambivalente/negativa & Diablo \\
\hline 10. Caballo & ratificada? & compleja/positiva & Orgullo/Nobleza \\
\hline 11. Cabra & - & ambivalente/negativa & Inconstancia \\
\hline 12. Camaleón & dudosa/involución & polivalente & Inconstancia \\
\hline 13. Camello & ratificada & polivalente/positiva & Sumisión/Pecador \\
\hline 14. Cangrejo & - & polivalente & Alma pecadora \\
\hline 15. Carnero & ratificada & positiva & Fuerza/Fecundidad \\
\hline 16. Castor & ratificada? & positiva & Pecador triunfante \\
\hline 17. Cerdo & ratificada & negativa & Impureza \\
\hline 18. Ciervo & ratificada & perfecta & Árbol de la Vida/CRISTO \\
\hline 19. Cigala & ratificada? & positiva & Misticismo \\
\hline 20. Cigüeña & superación & positiva & $\begin{array}{l}\text { Fidelidad conyugal y } \\
\text { filial }\end{array}$ \\
\hline 21. Cisne & ratificada & polivalerte/negativa & Autosacrificio \\
\hline 22. Codorniz & ratificada & positiva & Gracia de Dios \\
\hline 23. Cocodrilo & involución? & negativa & Hipocresia/Diablo \\
\hline 24. Concha & ratificada & positiva & Pecador/Peregrino \\
\hline 25. Cordero & ratificada & perfecta & Pureza/CRISTO \\
\hline 26. Cuervo & dudosa/involución? & Dual & Predicción/Demonio \\
\hline 27. Delfín & ratificada & positiva & Amor/CRISTO \\
\hline 28. Elefante & ratificada & positiva & Castidad/Pudor \\
\hline 29. Erizo & ratificada & positiva & Penitente \\
\hline 30. Escorpión & ratificada & negativa & Muerte/Sexo \\
\hline
\end{tabular}

patria, el gato es prudente e ingenioso y la serpiente sagaz. Hasta la vibora es la expresión paternal del amor a los súbditos. El oso simboliza la fortaleza en manejar armas contra los enemigos logrando la victoria, el tigre tiene ánimo veloz para vengar los agravios, el jabalí es valiente y el lobo posee un corazón constante que sufre las calamidades (como en los asedios) pero cuando se lanza a la lucha es implacable. Tanto es asi que no son pocas las órdenes militares o caballerescas que han elegido a un animal como símbolo. Ver a Pedro José DE ALdAzAval Compendio... de Armas ob. cit. 


\begin{tabular}{|c|c|c|c|}
\hline 31. Esponja & - & positiva & Receptividad \\
\hline 32. Gallo & ratificada & positiva & Vigilancia/Resurrección \\
\hline 33. Gato & involución? & negativa & Traición \\
\hline 34. Garza & ratificada & positiva & Generosidad/Fidelidad \\
\hline 35. Golondrina & ratificada & positiva & Oración/Resurrección \\
\hline 36. Grulla & ratificada & positiva & Alma buena/Justicia \\
\hline 37. Gusano & - & dual & Muerte (de tierra) \\
\hline & & & Resurrección (de seda) \\
\hline 38. Halcón & ratificada? & polivalente/positiva & Nobleza \\
\hline 39. Hiena & - & polivalente/negativa & Hermafroditismo \\
\hline 40. Hipopótamo & involución? & negativa & Mal \\
\hline 41. Hormiga & involución? & polivalente/negativa & Previsión/Adivinación \\
\hline 42. Jabali & involución & negativa & Lujuria/Gula \\
\hline 43. Lagarto & ratificada & polivalente/positiva & Luz de Cristo \\
\hline 44. Langosta & ratificada & negativa & Destrucción \\
\hline 45. Lechuza & involución & negativa & Muerte \\
\hline 46. León & ratificada & polivalencia/positiva & Generosidad/CRISTO \\
\hline 47. Leopardo & ratificada & polivalencia/negativa & Astucia \\
\hline 48. Liebre/Conejo & superación & polivalente/positiva & Fecundidad/Infinito \\
\hline 49. Lobo & involución? & negativa & Valor/Destrucción \\
\hline 50. Macho cabrio & ratificada & negativa & Diablo \\
\hline 51. Mariposa & ratificada & positiva & Alma/Luz \\
\hline 52. Mono & ratificada? & polivalente & Hombre \\
\hline 53. Murciélago & ratificada? & polivalente/negativa & Impureza \\
\hline 54. Oso & involución & negativa & Crueldad/Pereza \\
\hline 55. Ostra & ratificada & positiva & Encarnación \\
\hline 56. Oveja & ratificada & positiva & Los justos/caridad \\
\hline 57. Paloma & ratificada & perfecta & $\begin{array}{l}\text { CRISTO/Espiritu Santo. } \\
\text { Iglesia }\end{array}$ \\
\hline 58. Pantera & - & positiva & Belleza/CRISTO \\
\hline 59. Pavo & ratificada & positiva & Orgullo/Inmortalidad \\
\hline
\end{tabular}




\begin{tabular}{llll} 
60. Pelícano & - & positiva & Redención/CRISTO \\
61. Perro & involución? & polivalente/positiva & Fidelidad/Obediencia \\
62. Perdiz & - & negativa & Lujuria/Homosexualidad \\
63. Pulpo & - & polivalente/negativa & Astucia \\
64. Rana/Sapo & ratificada & dual & Herejia/Resurrección \\
65. Rata & ratificada & negativa & Enfermedad/Demonio \\
66. Rinoceronte & - & polivalente/positiva & Unicornio \\
67. Salamandra & - & positiva & Pureza/CRISTO \\
68. Serpiente & Dudosa/Involución? & dual & Demonio/CRISTO? \\
69. Tigre & Dudosa/Involución & negativa & Vanidad/Engaño \\
70. Topo & ratificada & negativa & Hereje/Demonio \\
71. Toro ${ }^{2}$ & ratificada & polivalente/negativa & Fuerza/Muerte \\
72. Tórtola & ratificada & positiva & Fidelidad \\
73. Tortuga & ratificada & positiva & Meditación \\
74. Vibora & ratificada & negativa & Mal \\
75. Zorro & involución & negativa & Demonio \\
\hline
\end{tabular}

2 Aunque el trabajo es más ambicioso, se tratan, también, en parte, los aspectos simbólicos del toro, ver "The Spanish Bulifight: some historical aspects, traditional interpretation and comments of archeozoological interest for the study of ritual slaughther", Morales, A., Morales, D.C., en The Symbolic Role of Animals in Archaeology, Ed. K. Ryan y P. Crabtree. MASCA Research Papers... Philadelphia, 1995. 